\title{
MICROSTRUCTURE AND PROPERTIES OF SPRAY ATOMIZED AND DEPOSITED SUPERALLOYS
}

\author{
Tian Shifan, Zaho Xianguo, Ren Liping, Liang Zhikai, Li Zhou and Mi Guofa \\ Institute of Aeronautical Materials Beijing, P.O. Box 81, 100095, P.R. China \\ John F. Radavich \\ Purdue University, West Lafayette, IN 47907 (USA)
}

\begin{abstract}
Spray atomization and deposition or Spray Forming (SF) has been a newly emerging science and technology in the field of materials development and production. SF makes it possible to combine the atomization of molten metals (Rapid Solidification) and the deposition of atomized droplcts (Dynamic Droplets Compaction) into one metallurgical operation to produce directly from liquid metal near-net shaped preform materials that have uniform chemical composition, refined grain and microstructure and improved properties.

At BIAM, fundamental work on the research and development of SF superalloys has been going on since 1990. A spray atomization and deposition facility has been designed and built with a strong vacuum evacuation system and minor leakage chamber. Inside the chamber a special designed water cooled multifunctional substrate/collector has been installed. The problem of contamination by the ceramic inclusions has been satisfactorily solved. A series of $\mathrm{Ni}$-base superalloys such as K403, K405, K417, GH95, and the intermetallic alloys IC-218, IC-6 etc. have been spray atomized and deposited. Various experiments and tests have been conducled on the samples taken from the diskshaped performs $(\psi 220-250 \times 50 \mathrm{~m} / \mathrm{m})$ and column-shaped billets $(\psi 170 \times 150 \mathrm{~m} / \mathrm{m})$ including macrostructure inspection on vertically sectioned slices, density measurements, microstructure examination by optical SEM or TEM, X-ray diffraction, HIP, hot deformation behavior and mechanical testing.

On the basis of results from the investigation, the following conclusions can be made: Spray formed superalloy materials have low oxygen content, homogeneous chemistry, refined microstructure and improved forgebility. HIP eliminates microporosity to make the preforms fully dense, which reduces the scatter of mechanical properties. The properties of SF superalloys may be adjusted through hot deformation and subsequent heat treatment to meet the specific requirements of a particular applications.
\end{abstract}

\section{Introduction}

\section{The Process Description}

Spray Forming (SF) or spray atomization and deposition has been an emerging science and technology in the field of materials development and production in recent years [1]. It is a most effective and economical way of making large preforms weighing from a few $\mathrm{kgs}$ to several thousand $\mathrm{kgs}$ by means of rapid solidification. The SF process may be described principally as follows: (see also schematic representation in Figures 1 and 2). The molten stream of a superheated melt of metal (or alloy) is being broken and disintegrated at the exit end of the metal delivery tube by a stream of high speed gas and is atomized into a spray of highly dispersed fine droplets with a specific particle size distribution. Being accelerated by the momentum of the atomizing gas stream, these atomized droplets simultaneously undergo extensive heat exchange during flight. While droplets under certain critical size solidify into fine solid particles, large ones remain in liquid state with different undercooling. In between these two extremes, medium sized droplets become semi-solid with different contents

$$
\text { Superalloys } 1996
$$

Edited by R. D. Kissinger, D. J. Deye, D. L. Anton,

A. D. Cetel, M. V. Nathal, T. M. Pollock, and D. A. Woodford

The Minerals, Metals \& Materials Society, 1996 of liquid phase (mushy state). These particles collide at high velocity $(25 \sim 75 \mathrm{~m} / \mathrm{s})$ upon the substrate - or collector surface where they adhere and deform to form a thin semi-liquid layer on its top where it continuously solidifies and grows into a large piece of integral dense solid preform. Thus SF makes it possible to combine the atomization of molten metals (Rapid Solidification) and the deposition of atomized droplets (Dynamic Droplets Compaction) into a one-step metallurgical operation to produce directly near-net shaped preforms/materials that have uniform chemical composition, refined grain and microstructure and improved properties. Because of its potential technical and economical benefits, the SF process has received a great deal of attention and has reached the stage of industrial application [2-4].

\section{R \& D of SF Superalloys at BIAM}

The technology of spray formed superalloys has entered the stage of practical applications. At BIAM, fundamental work on the research and development of spray formed superalloys has been going on since 1990 


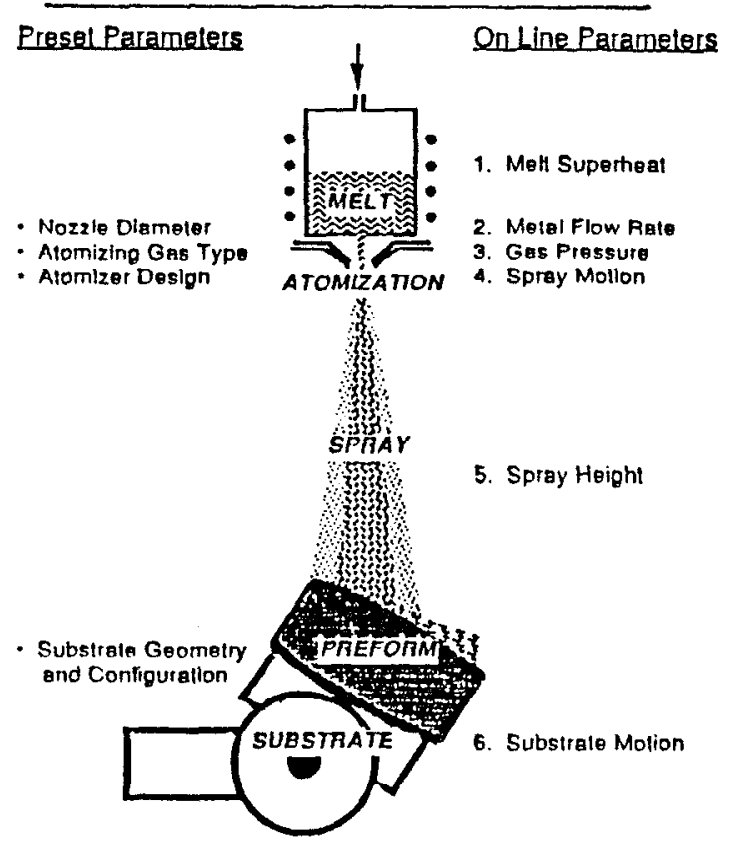

Figure 1. Schematic of the Osprey ${ }^{\mathrm{TM}}$ deposition process showing the formation of a disk/billet, and the process parameters which can be manipulated to optimize preform shape, structure and yield.

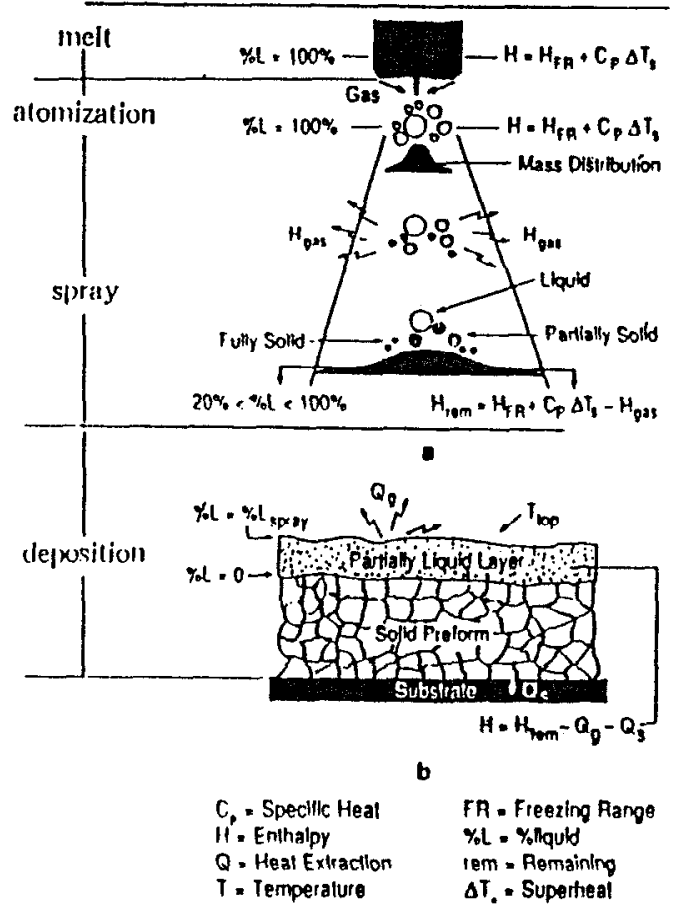

Figure 2. Schematic representation of spray casting showing the physical and thermal states of (a) the spray and (b) the deposit.

Table 1. Chemical Composition of Superalloys Processed by Spray Forming.

\begin{tabular}{|c|c|c|c|c|c|c|c|c|c|c|c|c|c|c|}
\hline Alloy & $C$ & $\mathrm{Cr}$ & $\mathrm{Co}$ & Mo & $\mathrm{W}$ & $\mathrm{Al}$ & $\mathrm{Ti}$ & $\bar{B}$ & $\mathrm{Zr}$ & Others & $\begin{array}{l}\text { Density } \\
\mathrm{g} / \mathrm{cm}^{3}\end{array}$ & $\begin{array}{l}\mathrm{Tm} \\
{ }^{\circ} \mathrm{C}\end{array}$ & $\begin{array}{c}\gamma \\
\text { vol \% }\end{array}$ & $\begin{array}{l}\mathrm{T}_{\mathbf{Y}^{\prime}} \\
{ }^{\circ} \mathrm{C}\end{array}$ \\
\hline Nimoniel 15 & 0.15 & 15.0 & 14.5 & 4.0 & - & 5.0 & 4.0 & 0.016 & 0.04 & & 7.80 & 1315 & 50 & 1150 \\
\hline Mar M002 & 0.15 & 9.0 & 10.0 & $<0.5$ & 10.0 & 5.5 & 1.5 & 0.015 & 0.05 & $\mathrm{Ta} 2.5, \mathrm{Hfl} .5$ & 8.5 & 1280 & 60 & 1250 \\
\hline Rene' 80 & 0.17 & 14.0 & 9.5 & 4.0 & 4.0 & 3.0 & 5.0 & 0.015 & 0.03 & & 8.16 & 1320 & - & \\
\hline IN-100 & 0.24 & 10.0 & 15.0 & 3.0 & 0.87 & 5.6 & 5.0 & 0.015 & 0.06 & & 7.8 & 1340 & 62 & \\
\hline Merl-76 & 0.03 & 12.5 & 18.5 & 3.2 & 0.8 & 5.0 & 4.4 & 0.02 & 0.05 & NB-1.4 & 7.83 & & 64 & 1185 \\
\hline IN-718 & 0.04 & 18.0 & - & 2.90 & - & 0.57 & 0.95 & 0.006 & 0.0 & $\mathrm{Fe}-20$ & 8.24 & 1320 & & 1020 \\
\hline Rene' -95 & 0.06 & 13.0 & 8.0 & 3.50 & 3.5 & 3.5 & 2.5 & 0.01 & 0.05 & NB-3.5 & 8.3 & 1348 & 49 & 1160 \\
\hline IN 625 & 0.03 & 21.0 & $<1.0$ & 9.0 & & 0.3 & 0.2 & & & $\mathrm{Nb} 4, \mathrm{Fe}<5$ & 8.44 & 1350 & - & 1020 \\
\hline Waspaloy & 0.07 & 19.5 & 13.5 & $4 ?$ & - & 1.4 & 3.0 & 0.01 & 0.06 & & 8.22 & 1360 & 20 & 1020 \\
\hline Rene' -41 & 0.09 & 19.0 & 11.0 & 9.8 & - & 1.6 & 3.25 & 0.01 & & & 8.27 & 1371 & - & 1050 \\
\hline$A F-115$ & 0.05 & 10.7 & 15.0 & 2.8 & 5.9 & 3.8 & 3.9 & 0.02 & 0.05 & $\mathrm{Nb} 1.7, \mathrm{Ta} 1.5$ & 8.33 & - & 55 & \\
\hline AF2-1DA & 0.04 & 12.0 & 10.0 & 2.75 & 6.5 & 4.6 & 2.8 & 0.015 & 0.10 & & 8.33 & - & 52 & \\
\hline Astroloy & 0.02 & 15.0 & 17.0 & 5.0 & - & 4.0 & 3.5 & 0.03 & 0.045 & & 8.0 & - & 45 & 1120 \\
\hline U-720 & 0.032 & 17.8 & 14.5 & 2.0 & 1.2 & 2.45 & 5.0 & 0.032 & 0.03 & & 8.1 & 1245 & - & 1140 \\
\hline Rene' 88DT & 0.03 & 16 & 13 & 4 & 4 & 2.1 & 3.7 & 0.03 & 0.03 & $\mathrm{Nb}-0.7$ & 8.36 & - & 40 & 1105 \\
\hline
\end{tabular}


[5]. A number of heavily alloyed high strength Ni base alloys have been spray atomized and evaluated. The chemical compositions are listed in Table 1. A spray atomization and deposition facility has been designed and built with a strong vacuum evacuation system and minor leakage chamber. Inside the chamber a special designed water cooled multifunctional substrate/collector [6] has been installed that can be tilted and eccentrically fixed. During the process deposition, it rotates around the axis of the preform growth and at the same time may move down along the axis to maintain the deposition distance to be optimum as the deposit builds up. Because the key process parameters can be adjusted, the desired shape of the preform can be made. The problem of contamination by the ceramic / inclusions has been satisfactorily solved using the clean melting technology from research and devclopment carried out at BIAM. This creates the potential for the application of the spray formed superalloys for the critical rotating turbine components. A number of Ni-base superalloys such as K403, K405, K417, Rene 95 and the intermetallic alloys IC-218, IC-6, etc. have been spray formed, and the test results from this work were encouraging. Test results of two Ni-base superalloys with different alloying level and $\gamma$ vol. \% have been selected for presentation in this paper.

\section{Experimental Procedure}

The materials used for the spray forming processing were vacuum melted master alloy as cast ingots and some revert. Disc shaped preforms were made in the experimental facility. The values of the primary experimental variables used during the experiment are listed in Table 2.

Table 2. Experimental Variables Used for SF

\begin{tabular}{|lcc|}
\hline Variable Alloy Designation & A & B \\
\hline Charge weight $(\mathrm{kg})$ & 18.7 & $11.3 \sim 14.5$ \\
Superheat $\left({ }^{\circ} \mathrm{C}\right)$ & 200 & $150-20$ \\
Atomizing gas & Pure $\mathrm{N}_{2}$ & Pure $\mathrm{N}_{2}$ \\
Atomization pressure $(\mathrm{MPa})$ & $211.0 / 1.5$ & \\
Atomization time(s) & 120 & $46-60$ \\
Deposition distance $(\mathrm{mm})$ & 340 & $390-400$ \\
Collector position & eccentric, tilted & eccentric, tilted \\
Collector movement & spin, synchronic & spin, synchronic \\
& descending & descending \\
Number of preform for test & 1 & 4 \\
\hline
\end{tabular}

Table 3. Chemical Composition
A vertically sectioned slice $10 \sim 15 \mathrm{~mm}$ thick was cut along the center line of the preform and prepared for macroetching to revcal any possiblc metallurgical defccts. Then the macroetched slice was cut by electrosparking into small pieces for density measurements and metallographic examinations to detect the presence of any ceramic inclusions. Hot isostatic pressing was cond on preform alloy $A$ and one of the preforms of alloy B. Samples cut from alloy B were used for hot deformation tests at different strain rates and temperatures. The rest of the two preforms of alloy $B$ were hot forged to a pancake on a 1250 ton forging press.

Chemical analysis of alloy composition and gas content were first run and a detailed microstructural study was carried out by optical metallography and SEM on alloy B. Mechanical property tests were made on samples having different thermal treatments.

\section{Results and Discussion}

\section{Chemical Composition}

The results of chemical analysis of alloys A and B are listed in Table 3.

The results show that SF has little effect on alloying elements. The gas content indicates almost no hydrogen in the preform. Since the time the alloy is in a liquid state is very short $\left(-10^{3} \mathrm{sec}\right)$ and is exposed to an inert environment of pure $\mathrm{N}_{2}$ (or Ar), the oxygen pick-up is very limited. The oxygen in the preform is very low and at the same level as in the master alloy. As the nitrogen was used as atomizing gas in these experiments, its content in both alloy $\mathrm{A}$ and $\mathrm{B}$ is relatively high especially for the alloy containing higher $\mathrm{Cr} \%$. The solubility of $\mathrm{N}_{2}$ in $\mathrm{Ni}$-base alloys is very low and generally exists in the form of a nitride. In the SF superalloys containing $\mathrm{Ti}$ and $\mathrm{Nb}$, the nitride usually is in the form of $(\mathrm{Ti}, \mathrm{Nb})(\mathrm{CN})$. Owing to the high cooling rate during the atomization, many of the primary carbonitrides that precipitated out of the liquid were finely dispersed and had no detrimental effects on the mechanical properties.

\section{Deformation Behavior}

Hot deformation tests were conducted on the samples of alloy B at temperatures of $1120,1100,1080$ and $1020^{\circ} \mathrm{C}$ and at a strain rate range $\varepsilon=3.2 \times 10^{-2} \sim 2 \times 10^{-4}$. Results show that at all temperature and strain rate tests the alloy has good hot ductility. The hot ductility will be improved and flow stress reduced as the temperature increases and strain rate decreases. On the basis of the hot deformation tests, two

\begin{tabular}{|cccccccccccc|}
\hline Alloy & $\mathrm{C}$ & $\mathrm{Co}$ & $\begin{array}{c}\mathrm{Cr} \\
\text { wt.\% }\end{array}$ & $\mathrm{Mo}$ & $\mathrm{Al}$ & $\mathrm{Ti}$ & other & $\begin{array}{c}\gamma^{\prime} \\
\text { vol. } \%\end{array}$ & $\mathrm{H}$ & $\begin{array}{c}\mathrm{O}_{2} \\
\text { ppm }\end{array}$ & $\mathrm{N}_{2}$ \\
\hline $\mathrm{A}$ & 0.14 & 14.8 & 9.02 & 3.3 & 5.32 & 4.40 & $\mathrm{~V} 0.73$ & 60 & 1 & 14 & 200 \\
$\mathrm{~B}$ & 0.06 & 9.95 & 14.7 & 5.11 & 2.87 & 2.66 & $\mathrm{Nb} 2.65$ & 35 & - & 15 & 320 \\
\hline
\end{tabular}


billets of the preform alloy $B$ were forged with one upset $>60 \%$. No cracking in the forged billets was found.

\section{Mechanical Properties}

The mechanical properties for alloy $\mathrm{A}$ and $\mathrm{B}$ are summarized in Tables 4 and 5, respectively. Since alloy A may be used in cast condition, test data of the cast alloy A were listed for comparison. It is obvious that SF increases the yield and rupture strength remarkably. While HIP decreases the scatter of the properties and considerably improves the ductility, the yield strength is somewhat reduced. The SEM observation of the fracture surface of the test bars indicates that the porosity has been healed by HIPing. If the tensile properties of the asHIPed powder metallurgy alloy of the same composition as alloy $\mathrm{A}: \sigma_{\mathrm{b}}=1125 \mathrm{MPa}, \delta_{5}=8.0 \%$ which were reported in [7] are compared with those listed in Table 4, the properties of alloy $A$ in both spray deposited and HIPed condition are superior.

Table 4. Tensile Properties of Alloy A

\begin{tabular}{|ccrrrrr|}
\hline No. of test & condition & $\mathrm{T}$ test ${ }^{\circ} \mathrm{C}$ & $\sigma_{\mathbf{b}} \mathrm{MPa}$ & $\sigma_{0.2} \mathrm{MPa}$ & $\delta_{5} \%$ & $\Psi \%$ \\
\hline 24 & $\mathrm{SF}$ & $20^{\circ} \mathrm{C}$ & 1306 & 904 & 18.0 & 15.8 \\
28 & $\mathrm{SF}$ & $20^{\circ} \mathrm{C}$ & 1393 & 927 & 21.2 & 20.4 \\
12 & $\mathrm{HIP}+\mathrm{HT}$ & $20^{\circ} \mathrm{C}$ & 1373 & 799 & 33.2 & 29.2 \\
21 & $\mathrm{HIP}+\mathrm{HT}$ & $20^{\circ} \mathrm{C}$ & 1368 & 810 & 32.4 & 29.9 \\
16 & $\mathrm{HIP}+\mathrm{HT}$ & $700^{\circ} \mathrm{C}$ & 1053 & 1 & 23.0 & 23.1 \\
23 & $\mathrm{HIP}+\mathrm{HT}$ & $700^{\circ} \mathrm{C}$ & $\mathrm{I} 04 \mathrm{~J}$ & $/$ & 23.2 & 32.0 \\
& as cast & $20^{\circ} \mathrm{C}$ & 990 & 765 & 11.5 & 19.0 \\
& as cast & $700^{\circ} \mathrm{C}$ & 1000 & 774 & 13.0 & 2.0 \\
\hline
\end{tabular}

*(Handbook of the Aeronautical Materials of China), vol. 2 , p. 651 .

Table 5. Mechanical Properties of Alloy B

\begin{tabular}{|c|c|c|c|c|c|c|c|}
\hline \multirow[b]{2}{*}{$\begin{array}{l}\text { No. } \\
\text { Pref. }\end{array}$} & \multirow[b]{2}{*}{$\begin{array}{c}\text { Test } \\
\text { Condition }\end{array}$} & \multicolumn{4}{|c|}{ Tensile } & \multirow{2}{*}{$\begin{array}{c}\text { Stress Ruplure } \\
650^{\circ} \mathrm{C} / 834 \mathrm{MPa} \\
\tau(\mathrm{h})\end{array}$} & \multirow{2}{*}{$\begin{array}{c}\text { Impact } \\
\text { Ak } \\
\mathrm{J}\end{array}$} \\
\hline & & $\begin{array}{c}\sigma_{\mathrm{b}} \\
\mathrm{MPa}\end{array}$ & $\begin{array}{l}\sigma_{0.2} \\
M P_{a}\end{array}$ & $\begin{array}{l}\delta \\
\%\end{array}$ & $\underset{\psi}{\Psi}$ & & \\
\hline E01 & SF & 1356 & 898 & 26.3 & 36.6 & $164: 50$ & 47.0 \\
\hline \multirow[t]{2}{*}{ E03 } & $\mathrm{F}+\mathrm{HT} 1$ & 1389 & 941 & 26.2 & 32.9 & - & 55.8 \\
\hline & & 1396 & 953 & 25.3 & 32.8 & - & 52.6 \\
\hline \multirow[t]{2}{*}{ E04 } & $\mathrm{F}+\mathrm{HT} 2$ & 1470 & 1067 & 22.8 & 22.4 & $144: 30$ & - \\
\hline & & 1466 & 1060 & 21.6 & 23.4 & 205:10 & 62.7 \\
\hline \multicolumn{2}{|c|}{ Specification } & 1210 & 755 & 13 & 14 & 50 & 24 \\
\hline
\end{tabular}

1) $\mathrm{HT} 1-1140^{\circ} \mathrm{C}$ solution treated

2) $\mathrm{HT} 2-1080^{\circ} \mathrm{C}$ solution treated.

Data listed in Table 5 show the properties of alloy B in the as deposited condition were much higher than that required by the specification. Low temperature solution treatment improves the rupturc and yicld strcngth as well as the impact properties while maintaining the ductility and $650^{\circ} \mathrm{C}$ stress rupture property at a relatively high level. A high temperature solution treatment didn't improve the properties as much as the low solution trcatment did.

\section{Macrostructure and Density}

Examination of macro etched sample shows the macrostructure to be dense with a little porosity, and no coarse dendritic grains were found as normally seen in cast alloys. Porosity is mainly concentrated near the bottom surface of the preform wherc the atomized droplets first impact against cooled substrate. Some porosity was found at the periphery and near the top surface of the preform at the very beginmning of the deposition process. The average density of the entire preform is about $98.8 \%$ of theoretical, and after HIP, the alloy density may reach $99.9 \%-100 \%$.

\section{Microstructure}

Optical studies revealed a fine uniform equiaxed grain structure in all alloys in the as-deposited condition. Alloys with high carbon contents such as alloy A will occasionally show PPB within $3-5 \mathrm{~mm}$ range of the bottom surface. Eutectic $\gamma$ islands normally found in high $\mathrm{Al}+\mathrm{Ti}$ alloys are rarely seen in spray formed materials.

Higher resolution detailed structural studies of alloy $B$ were carried out with the SEM, EDS, and X-ray diffraction techniques on the as-deposited, HIPed, HIPed+ forged, and heat treated samples. The asdeposited material contained some porosity which was closed by HIPing. The grains are uniform and range from 10-25 microns in size. Primary carbides are well

distributed and have a range of sizes, some as small as carbides seen in powder alloys. In addition to these small particles, there are some larger TiN particles in the matrix.

The grain boundaries show discrete carbide or other phases formed during the solidification while small round $\gamma$ is present in the grains due to the cooling from above the $\gamma$ solvus temperature. Figure 3 shows the various grain structures and the $\gamma+$ primary carbides in the matrix.

HIPing at $1150^{\circ} \mathrm{C}\left(2100^{\circ} \mathrm{F}\right) / 150 \mathrm{MPa} / 3$ hours and forging at $1110^{\circ} \mathrm{C}\left(2030^{\circ} \mathrm{F}\right)$ does not greatly change the grain size even though the temperatures may be above the $\gamma$ solvus. Primary carbides and other stable phases in the as-deposited material tend to pin down the grain boundaries unless the material is subjected to temperatures higher than those used in this study.

Samples which were HIPed and heat treated at $860^{\circ} \mathrm{C}\left(1580^{\circ} \mathrm{F}\right) / 8$ hours $+788^{\circ} \mathrm{C}\left(1450^{\circ} \mathrm{F}\right) / 16$ hours show small discrette particles at the grain boundaries and the $\gamma$ is slightly larger than the as-cooled $\gamma^{\prime}$, Figure 4 .

To appreciate the size difference of spray cast microstructures, an ingot sample of alloy B was evaluated for segregation and the nature of the microstructures formed during slow cooling. Figure 5 shows large as-cast grains, large primary carbides and dendritic segregation. Alloy $\mathrm{B}$ has appreciable $\mathrm{Ti}$, and a $\mathrm{Ti}$ rich eta phase as well as accicular needles are found together in the dendritic segregation areas. These phases are not found ih spray cast materials of the same composition. The primary carbides of alloy B ingot material form the normal Chinese script morphology while the $\gamma$ shape and size varies with the degree of $\mathrm{Al}+\mathrm{Ti}$ segregation and the ingot cooling rate. 


\section{Phase Identification}

Insitu EDS analyses of the small particles showed strong $\mathrm{Nb}+\mathrm{Ti}$ and appreciable Mo contents, but the surrounding matrix excitation prevented phase identification by composition alone. Large TiN particles were easily identified by their high $\mathrm{Ti}$ content and their reddish clor when viewed optically.

Extraction of all the small particles in the spray

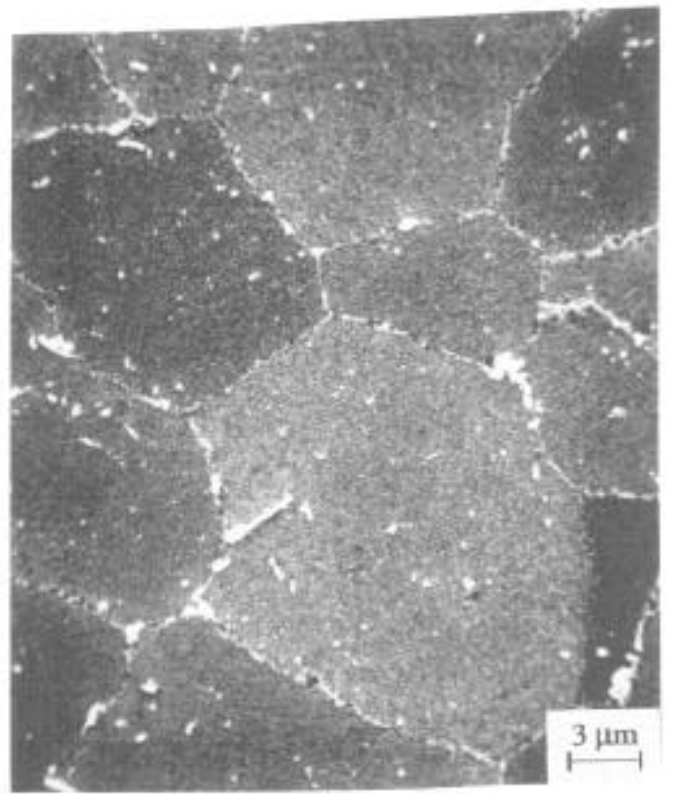

(a)

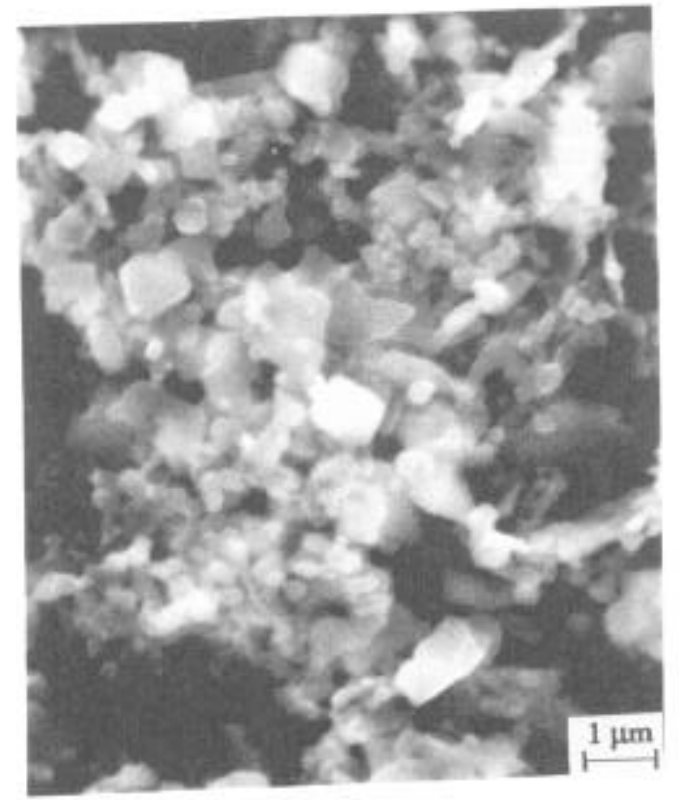

(c) deposited condition was carried out for X-fay diffraction studies. The floating residue had a reddish hue which confirmed the presence of TiN particles in the residue.

The X-fay diffraction study showed that only two phases were extracted, an MC phase with a lattice parameter of $4.388 \AA$ and $\mathrm{TiN}$ with a parameter of 4.246 A Some of the TiN in the residue is the large TiN particles seen optically.

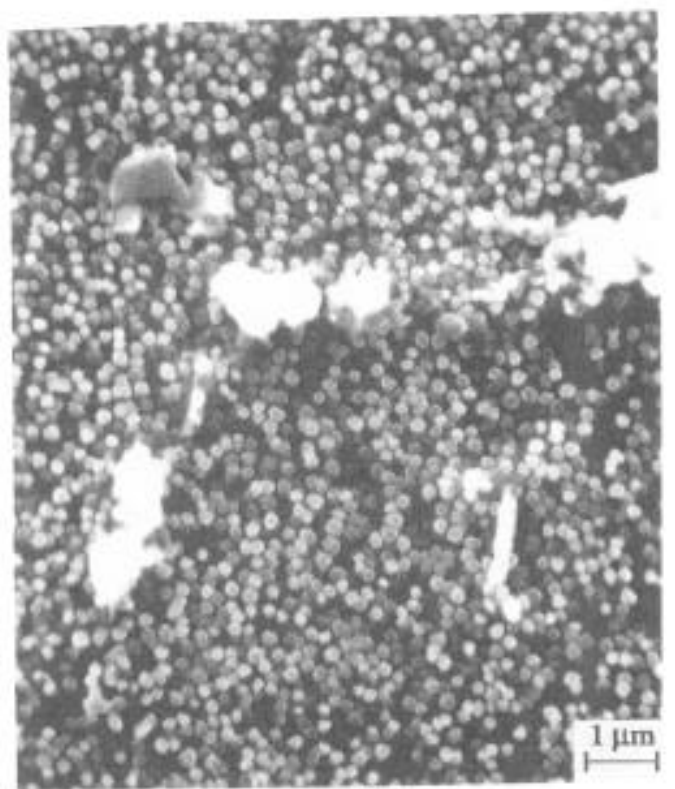

(b)
Figure 3. As Deposited

(a) Grain Structure.

(b) $\gamma$ Phase.

(c) Extracted Carbides and Nitrides. 

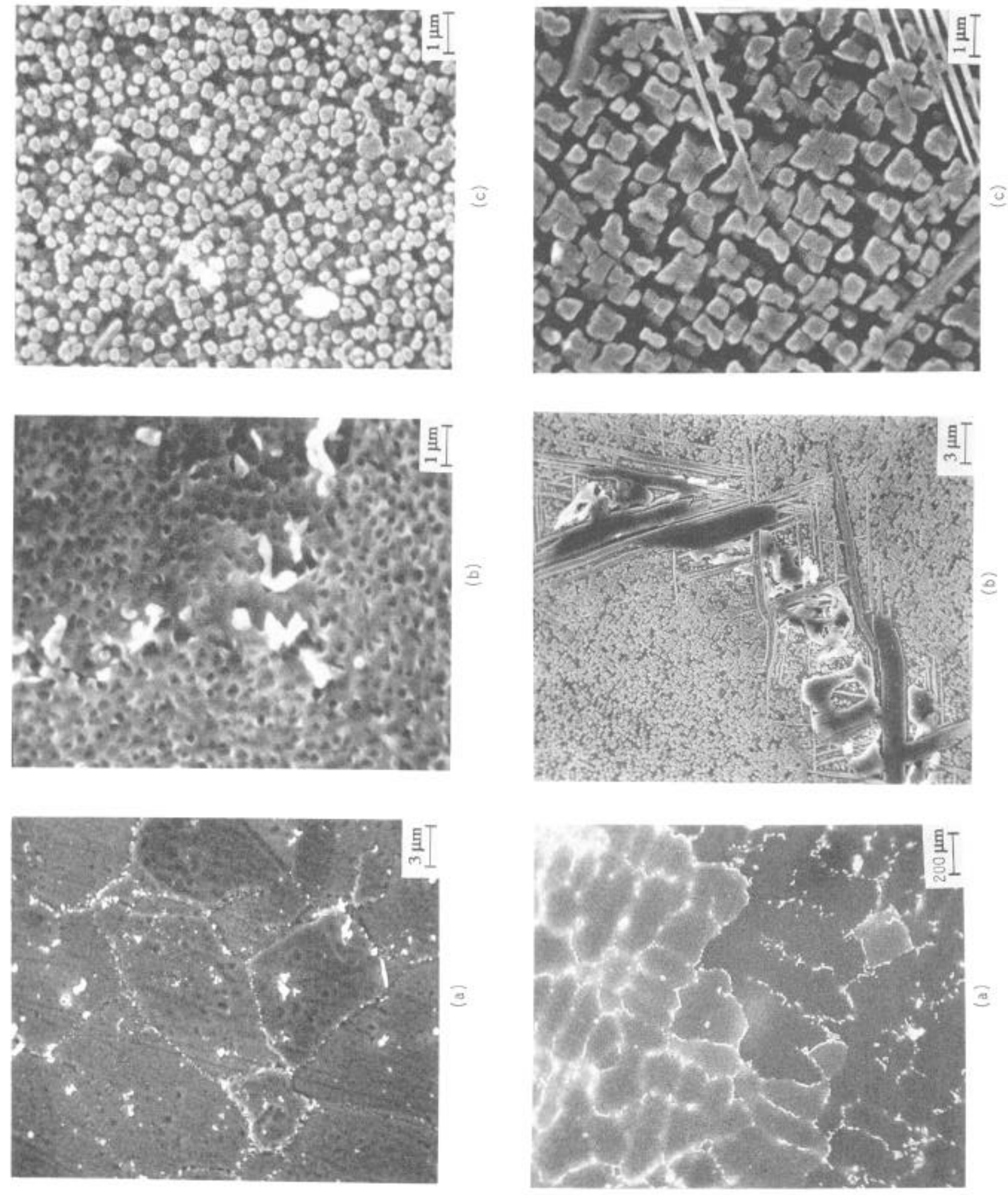

Figure 4. HIP+ Heat Treated.

(a) Grain Structure.

(b) Grain Boundaries.

(c) $\gamma$ Phase.

Figure 5. Ingot Structures.

(a) Grain Structure

(b) Eta Phase.

(c) $\gamma$ Phase. 


\section{Long Time Stability}

In order to verify the chemical homogeneily of the SF superalloys, alloy A was selected for a sigma phase stability test. This is hecause the alloy A composition with high $\mathrm{Al}+\mathrm{Ti}$ is prone to the precipitation of TCP $\sigma$ phase at the interdendritic area where most alloying elements are normally segregated in the as-cast condition. A sample cut from the preform alloy $\mathrm{A}$ was aged at the peak temperature of $\sigma$-precipitation $-850^{\circ} \mathrm{C}$ for 200 and 400 hrs. No $\sigma$ precipitation was detected.

\section{Discussion}

The observed improvement in mechanical properties in this study is in line with similar reported mechanical property studies of spray cast materials by Chang and Fiedler (8) and Prichard and Dalal (9). In both of these studies the mechanical property behavior was emphasized and so less structural characterization was carried out. Spray casting involves both solid and liquid materials solidifying in a temperature range where, depending on composition, $\mathrm{MC}, \mathrm{M}_{6} \mathrm{C}$, and $\mathrm{M}_{3} \mathrm{~B}_{2}$ can form discrete or continuous structures.

Because of the varying rates of solidification during spray casting, various size particles can form, some of which approach the size of tine particles in powder materials. Some of the particles show distinct shapes which others have a splat-like nature. Because of the high nitrogen content shown in Table 3 , small nitrogen rich particles should be present similar in size to the carbide particles. However, the very large TiN particles present in the spray cast material appear to be too large to form during the spray casting, and therefore, it appears that the TiN particles (which were not melted) are carried over from the master melt alloy. A study of the microstructural nature of the master alloy should be further studied to avoid large inclusions which may serve as crack initiation sites.

\section{Conclusions}

1. Spray formed superalloys have low oxygen content, homogeneous chemistry, refined microstructure and improved forgebility.

2. HIPing eliminates the microporosity and makes the preform fully dense, which reduces the scatter of mechanical properties.

3. The properties of SF superalloy may be adjusted through hot deformation and subsequent heat treatment to meet the specific requirements of a particular application.

\section{Acknowledgements}

The Acronautical Science Foundation and the National Natural Science Foundation are greatly acknowledged for their financial support.

\section{References}

1. Spray Forming: Science, Technology Application, 1992, P/M World Congress, ed. Alan Lawley.

2. Internal Report of BIAM, 1994.

3. Proceedings of the 1st. ICSF, 1991.

4. Proceedings of the 2nd. ICSF, 1993.

5. Internal Report of BIAM, 1988.

6. Internal Report of BIAM, 1993.

7. N. J. Grant, Metall. Trans. Vol. 23A, No. 4 pl083 10.93 .

8. K. M. Chang and H. C. Fiedler, "Spray Forming High Strength Superalloys," pp. 475-484, Superalloys 1988, TMS.

9. P. D. Prichard and R. P. Dalal, "Spray Cast-X Superalloy for Aerospace Applications," pp. 205216, Superalloy 1992, TMS. 